\title{
Negative plant-soil feedback and species coexistence
}

\author{
Giuliano Bonanomi, Francesco Giannino and Stefano Mazzoleni
}

Bonanomi, G., Giannino, F. and Mazzoleni, S. 2005. Negative plant-soil feedback and species coexistence. - Oikos 111: 311-321.

\begin{abstract}
Different mechanisms, including equilibrium and non-equilibrium processes, have been taken into account as possible theoretical explanations of species coexistence. Despite the ample evidence on the existence of negative plant-soil feedback in both agriculture and natural vegetation, the role of these processes in the organization and dynamics of plant communities has so far been neglected. In this study, simulations by an individual-based competition model show how the intensity of negative feedback on individual plant performance can produce faster successional dynamics and allow species coexistence in two- and multi-species systems. The results show that even low levels of negative plant-soil feedback can enable species coexistence and often produce cyclic population dynamics. Moreover, the model highlights how negative feedback can generate positive reciprocal interspecific interactions at the population level, despite the fact that only competitive interactions is present between individual plants. In fact, competitive effects occur on a short-term scale, but positive reciprocal species interactions emerge only if negative feedback affects all species and if longer periods of simulation, more than the species life span, are considered. An important outcome of the model is the evidence that the effects at population level are timescale-dependent, thus showing the limitation of short-term species removal experiments used in traditional competition studies.
\end{abstract}

G. Bonanomi, F. Giannino and S. Mazzoleni, Dip. di Arboricoltura, Botanica e Patologia vegetale, Univ. of Naples Federico II, via Università 100, IT-80055 Portici 80055 (NA), Italy(stefano.mazzoleni@unina.it).

The paradox of biodiversity (Hutchinson 1958, Grubb 1977), i.e. the difficulty of explaining the coexistence of species in the same ecological space, has recently been considered resolved for several organisms, such as plankton (Huisman and Weissing 1999), inter-tidal organisms (Worm and Karez 2002) and terrestrial plants (Fargione and Tilman 2002). Different mechanisms have been taken into account as possible theoretical solutions to the paradox, including equilibrium mechanisms through niche partitioning (Fitter 1986, Tilman 1994) or non-equilibrium coexistence dynamics (Huston 1994) related to disturbance (Connell 1978, Sousa 1984), predation (Paine 1966) and fluctuations of environmental conditions (Chesson 2000).

Local environmental heterogeneity created by individual plants has been suggested as an other important, but under-investigated, issue (Tilman and Pacala 1993) for the understanding of both species coexistence and successional dynamics. A specific case of plant-induced soil heterogeneity is the so-called plant-soil "negative feedback" (Bever 1994), i.e. a relative negative condition for the establishment, the growth and the reproduction of individuals under their parent plants. In agriculture, this has been a well known phenomena since ancient times, and is often reported as the 'soil sickness' or 'orchard replant' problem (Patrick et al. 1963, Waller et al. 1986). This negative feedback has been seldom considered in natural ecosystems (van der Putten et al. 1988, Zucconi 1994) despite some early demonstrations of its existence (Florence 1965, Webb et al. 1967, McNaughton 1968). More recently, this type of plantsoil interaction has received greater scientific attention 
and has been reported in relation to succession (van der Putten et al. 1993), coexistence (Bever 1994), and invasion (Klironomos 2002) processes in tropical and temperate forests (Fox 1977, Streng et al. 1989, Wills et al. 1997), coastal dunes (Van der Putten et al. 1993, Little and Maun 1996), old fields and grassland (Bever 1994, Holah and Alexander 1999, Blomqvist et al. 2000, Olff et al. 2000).

Detrimental effects of negative feedback have been described for different aspects of a plant's life cycle including seed germination (Rice 1984, Li and Romane 1997), seedling survival (Packer and Clay 2000), individual growth (Miller 1996), vegetative propagation (Van der Putten et al. 1988, Blomqvist et al. 2000, Olff et al. 2000), and seed production. Most studies have concerned single species performance (Van der Putten et al. 1993, Holah and Alexander 1999), whereas only few dealt with the indirect effect of negative feedback on interspecific competition interactions (but see Van der Putten and Peters 1997, Bonanomi and Mazzoleni 2005).

Several mechanisms have been proposed to explain the source of negative feedback including soil nutrient depletion, the build-up of soil-borne pathogens and parasite populations (De Rooij-van Der Goes 1995, Packer and Clay 2000), the changing community composition of soil microbial organisms (Bever 1994), and the release of allelopathic compounds during organic matter decomposition (Proebsting and Gilmore 1940, Patrick 1971, Chou and Lin 1976, Miller 1996, Armstrong and Armstrong 2001). In this latter case, negative feedback has also been defined as autotoxicity (Singh et al. 1999). Experimentally, negative feedback intensity has been found related to soil history (sensu Zucconi 1996, Klironomos 2002) and fertility (Wedin and Tilman 1993). Moreover, negative feedback has been demonstrated to be strongly species-specific (Webb et al. 1967, Newman and Rovira 1975, Rice 1984, Van der Putten et al. 1993, Bever 1994, Zucconi 1996, Singh et al. 1999, Olff et al. 2000, Packer and Clay 2000, Klironomos 2002) and, although the underling mechanisms are still unclear, this suggests a potential important role in changing the competitive hierarchies of coexisting species (Bever 2003).

A possible role of negative feedback is on vegetation succession. For primary succession starting over bare substrate, facilitation processes are pivotal to allow the establishment of later successional species and the consequent exclusion of early colonizers (Connel and Slatyer 1977, Miles and Walton 1993). Traditionally, competition for nitrogen and light is considered the central mechanism of secondary successions (Tilman 1985) though some authors (Rice 1984, Van der Putten 2003) have hypothesized that negative feedback could affect the rate of species turnover during a succession because of the reduced capability of pioneer species to regenerate on soil that supported their own parent plants. Nevertheless, this mechanism has not been considered in common views of succession (Connel and Slatyer 1977, Tilman 1988).

Early modelling work by Bever et al. (1997) showed how positive and negative feedback could reduce and increase species diversity, respectively. In a later investigation, using a Lotka-Volterra type model, Bever (2003) also demonstrated how negative feedback could enable the coexistence of strongly competing species. Zucconi (1994) suggested using a "verbal" model (sensu Tilman and Lehman 2001), that negative feedback could produce indirect positive (facilitatory) species interactions. Although the experimental evidence of plant-soil negative feedback is now abundant, the role of this process in changing the sign and strength (Miller 1994) of species interaction and the consequences for plant community organization has been rarely investigated (Bever et al. 1997, 2003).

In this paper, the role of negative feedback on individual interaction, population dynamics, and organization of plant community, is discussed by an individual-based competition model. This type of model, unlike the population modelling approach, allows a more realistic representation of the plant community, both in terms of structure and dynamics. Specifically, the following hypotheses were tested: (1) increasing negative feedback intensity can produce faster successional dynamics (2) negative feedback can allow species coexistence even in multi-species systems and (3) positive indirect reciprocal interaction can rise between competing species in presence of negative feedback.

\section{Model description}

A model is proposed where a negative soil feedback affects germination, growth and seed production of different plant species. No negative plant-soil interactions occur when a plant grows on a primary substrate or on a soil influenced by the growth of a different species, whereas negative feedback is activated when a seed falls on a soil previously marked by the same plant species.

The model has been implemented according to a non spatially-explicit (Klausmeier and Tilman 2002) individual-based modelling approach (DeAngelis and Gross 1992, Uchmanski and Grimm 1996). A population is represented as a set of individuals, each characterized by the relative species parameters and behaviours (Grimm 1999). The model was written by the system dynamic software SIMILE (C) (Muetzelfeldt and Massheder 2003). A working version of the SIMILE model can be down-loaded from www.ecoap.unina.it/AN 


\section{Landscape}

The model considers a virtual space of 100 cells defined according to the following status (Table 1 provides an overview of symbols used, their interpretation, unit, and signed values):

$\mathrm{S}_{0}$ : free cell, never colonized in the past;

$\mathrm{S}_{1}$ : cell occupied by one species;

$\mathrm{S}_{0, \mathrm{j}}$ : free cell, used in the past by species $\mathrm{j}$.

Each cell can support the growth of only one individual plant. A cell remains marked by a species after its death until the completion of a new growth cycle by another plant individual.

\section{Plant growth}

Plant biomass growth is modelled as a logistic curve, according to the following equation:

$\frac{d B}{d t}=a_{i} B(1-N F)-b B^{2}$

where $\frac{\mathrm{dB}}{\mathrm{dt}}$ is the instantaneous rate of biomass change, $t$ is time, $B$ is biomass (grams), $a_{i}$ is the growth rate of species $i, b$ is the maintenance respiration coefficient and $\mathrm{NF}$ is the negative feedback coefficient. The latter can vary from 0 to 1 and it is activated for plants that establish in cells previously occupied by the same species. In absence of negative feedback $(\mathrm{NF}=0)$, plants show optimal growth, thus reaching a maximal biomass value of $\frac{\mathrm{a}}{\mathrm{b}}$. If $\mathrm{NF}>0$, plant growth becomes slower and the maximal biomass value is reduced to $\frac{a(1-N F)}{b}$. Despite the fact that a detrimental effect of negative feedback on longevity has been often recognised (Zucconi 1996), in order to reduce the model complexity, maximal age (individual mortality) is assumed as constant on all soil types and it is defined, for all plant species, as equal to $\mathrm{m}$ time steps of the individual life cycle. An individual reaching its maximal age is removed from the simulation, thus leaving free the corresponding cell, which remains marked as mentioned above.

\section{Seed production and dispersal}

Individual plants start to produce seeds after an age threshold value $(\mathrm{k})$ is reached. Seed production is proportional to biomass according to a conversion factor $s$ which defines the number of seeds per unit biomass.

Available seeds are distributed to soil cells by calculating the probability of selection of available cells which are free of vegetation cover. This is done, at each time step, by counting the number of cells of each category $\left(\mathrm{S}_{0}, \mathrm{~S}_{1}, \mathrm{~S}_{0, \mathrm{j}}\right)$ and assessing the following dispersal probability functions:

$\mathrm{P}_{0}^{\mathrm{i}}=\frac{\mathrm{S}_{0}}{100}$

$\mathrm{P}_{1}^{\mathrm{i}}=\frac{\mathrm{S}_{1}}{100}$

$\mathrm{P}_{0, j}^{\mathrm{i}}=\frac{\sum_{\mathrm{j} \neq \mathrm{i}} \mathrm{S}_{0, \mathrm{j}}}{100}$

$\mathrm{P}_{0, \mathrm{i}}^{\mathrm{i}}=\frac{\mathrm{S}_{0, \mathrm{i}}}{100}$

where $\mathrm{P}_{0}^{\mathrm{i}}, \mathrm{P}_{1}^{\mathrm{i}}$ are the probabilities of dispersal of a seed of species $\mathrm{i}$ in a $\mathrm{S}_{0}$ and $\mathrm{S}_{1}$ cells respectively. $\mathrm{P}_{0, \mathrm{j}}^{\mathrm{i}}$ and $\mathrm{P}_{0, \mathrm{i}}^{\mathrm{i}}$ are the probabilities of dispersal of species $i$ in free cells previously occupied by a different species or supporting a plant of the same species i respectively. For simplicity no dispersal limitation was introduced.

\section{Germination}

Germination is handled as a probabilistic function of cell type where the germination level is $80 \%$ in $\mathrm{S}_{0}$ cells, $0 \%$ in $\mathrm{S}_{1}$ cells, $80 \%$ in free cells previously occupied by a different species and $80 \% \times(1-\mathrm{NF})$ in free cells previously supporting plants of the same species. Asymmetric competition between adult plants and their offspring is thus assumed (Weiner 1990). After germination, starting biomass is set always equal to $0.01 \mathrm{~g}$.

Table 1. Overview of symbols used, their interpretation, unit, and assigned values.

\begin{tabular}{|c|c|c|c|}
\hline Symbol & Interpretation & Unit & Assigned value \\
\hline $\mathrm{S}_{0}$ & free cell, never supporting previous plant growth & $\ldots$ & $\ldots$ \\
\hline $\mathrm{S}_{1}$ & occupied cell of soil by one species & $\ldots$ & $\ldots$ \\
\hline $\mathrm{S}_{0, \mathrm{j}}$ & free cell, used in the past by species $\mathrm{j}$. & $\ldots$ & $\ldots$ \\
\hline B & plant biomass & $\mathrm{g}$ & $\ldots$ \\
\hline $\mathrm{a}_{\mathrm{i}}$ & plant growth rate & $\mathrm{yr}^{-1}$ & between 0.25 and 1 \\
\hline $\mathrm{b}$ & plant maintenance respiration coefficient & $\mathrm{yr}^{-1}$ & 0.1 \\
\hline NF & negative feedback parameter & $\%$ & between 0 to 1 \\
\hline $\mathrm{s}$ & number of seeds per unit biomass. & $\mathrm{g}^{-1}$ & $1 / 100$ \\
\hline $\mathrm{m}$ & plant maximal age & $\mathrm{yr}$ & between 7 to 10 \\
\hline $\mathrm{k}$ & plant maturity age & $\mathrm{yr}$ & 5 \\
\hline
\end{tabular}




\section{Initialization and simulation}

The simulations are run with a daily time step until stability is reached. At the start of the simulation, all available cells are free in state $S_{0}$, with an initial seeding of 1 seed for each considered species.

\section{Simulation exercises}

Model evaluation was performed through a series of simulation exercises because mathematical analysis is not possible in the case of individual-based modelling.

\section{Primary and secondary succession}

In the primary succession simulation, the colonizer species had a shorter life-span and an earlier seed production compared to the late successional species. These are common properties of pioneer species (Grime 1979). The late successional plants cannot grow in the starting soil, but only in the space derived from the mortality of the colonizer, thus mimicking a facilitation process (Connel and Slatyer 1977). In the primary succession simulations, the effect of three different levels of negative feedback on species turnover was tested $(\mathrm{NF}=0,0.3$ and 1$)$.

For the simulation of secondary successions for simplicity, all species had the same life-span and the same timing of seed production, but differed in their growth rates for the starting soil in order to have different competitive ability. In this exercise, the effects on coexistence of different levels of negative feedback $(\mathrm{NF}=0,0.2,0.3,0.5,0.9$ and 1$)$ and different species number (two, three and four) were analysed. Competition for the available space is the only interaction between species during the simulation, and is the consequence of the different growth rate between species. Competition intensity during simulation was calculated by the relative competition index (RCI). This index produces a standardized measure of growth as monoculture (only intraspecific competition) and in mixture with other species (intraspecific and interspecific competition; Grace 1995):

$\mathrm{RCI}=\left(\mathrm{PB}_{\mathrm{m}}-\mathrm{PB}_{\text {mix }}\right) / \mathrm{PB}_{\mathrm{m}}$

where $\mathrm{PB}_{\mathrm{m}}$ is the average population biomass in monoculture and $\mathrm{PB}_{\text {mix }}$ is the average population biomass in mixture. RCI values range between +1 and $-\infty$ : a value between 0 and +1 indicates competitive interaction, a negative value facilitative interactions and 0 a null interaction effect. To calculate the RCI, a test was performed with three replicate simulations of two species interactions and the same two species grown in monoculture.

The minimal necessary conditions for coexistence (indicated by the coexistence of interacting species at equilibrium) and the reciprocal positive interaction (shown by RCI values below zero for all the interacting species at equilibrium), were also studied by simulation. Specifically, the effects of different competition intensities, as produced by changing differences of growth rates of two competing species were addressed by repeated simulation until threshold values were found in each specific condition.

\section{Removal experiment}

By analogy with field removal experiments (Aarssen and Epp 1990), which are a commonly used test to investigate species response to disturbance and species interaction (Diaz et al. 2003), the simulation exercises included a full and abrupt elimination of biomass of one species. Vegetation removal was performed on a community in stable equilibrium in the presence of negative feedback on both species. The effects of species removal were tested by looking into the population dynamics of the remaining species. Simulation parameters for each of the simulation exercises are summarised in Table 1.

\section{Results}

\section{Succession and species coexistence}

In the absence of negative feedback, the simulation of a primary succession process (Fig. 1) showed an early colonization by the pioneer species on the bare soil. The later successional plants started to establish only after the death of some individuals of the first species, which released areas of secondary developed soil. The shift of dominance between species progressively excluded the early colonizer until a complete species turnover was reached. The presence of higher levels of negative feedback between the pioneer species and its growing substrate facilitated this successional process, which became proportionally faster (Fig. 1) by an anticipation of dominance of the later successional plants.

In the case of secondary succession, all species are able to colonise an open space, e.g. a forest clearance or an abandoned field. Without negative feedback, the simulation of two species interaction showed the clear advantage of a higher growth rate which results in the competitive exclusion of the inferior competitor (Fig. 2, $\mathrm{NF}=0$ ). In such conditions, species coexistence is possible only in the transient phase when free space is still available and the intensity of interspecific competition is low. Conversely, the presence of negative feedback allowed the survival and maintenance of both species: a stable equilibrium was reached, with a higher densities of the otherwise dominated species at increasing levels of negative feedback $(\mathrm{NF}=0,0.2,0.5$ and 

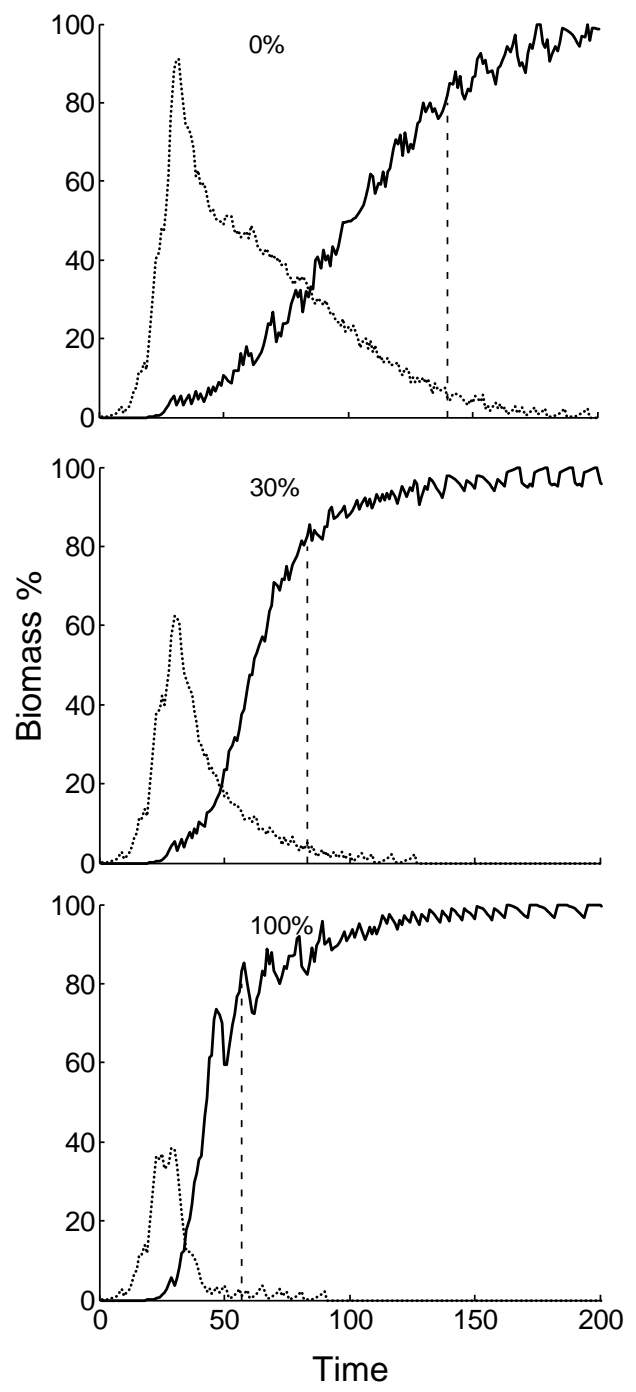

Fig. 1. Simulations of a simplified primary succession. An early colonizing species with a short life span $(\mathrm{m}=7$; dotted line) is followed by a later successional one with a longer life cycle $(\mathrm{m}=10$; solid line). According to facilitation theory the early colonizer has the ability to grow on bare soil $(\mathrm{a}=0.5$ for all type of cell) whereas the later successional plants are unable of early establishment $\left(\mathrm{a}=0\right.$ on $\mathrm{S}_{0}$ and $\mathrm{a}=0.6$ for the $\mathrm{S}_{0, \mathrm{j}}$ ) but show higher competitive ability on soils previously used by the pioneer species. Increasing levels of negative feedback for the pioneer species produced a faster rate of successional changes, with a progressive anticipation of the equilibrium conditions (vertical dashed lines show reaching of $90 \%$ of final biomass) Negative feedback intensity (\%) is indicated for each graph.

0.9). Interestingly, higher levels of negative feedback which could be related to known die-back phenomena reported in the literature (Armstrong and Armstrong 2001), produced larger oscillations of the simulated population density with shifts of dominance in the community (Fig. 2, NF $=0.9$ ). The amplitude of the oscillations is proportional to the intensity of the negative feedback.
Competitive exclusion is the final outcome of all simulations with absence of negative feedback (Fig. 3 $-0 \%$ ), irrespective of the number of interacting species. On the other hand, the occurrence of different levels of negative feedback allows coexistence in multi-species systems (Fig. $3-\mathrm{NF}=0.3,0.9$ and 1). Fluctuations of population size increase with the intensity of negative feedback levels in the two-species system (Fig. 3, 4), but interestingly they are smoothed with higher numbers of interacting species, also with a $100 \%$ level of negative feedback (Fig. 3, 4).

Different types of species interaction, evaluated by the $\mathrm{RCI}$, are apparent depending on the time-scale and according to the presence and relative intensity of negative feedback (Fig. 5). Without negative feedback, species interaction was always competitive with the RCI value approaching the maximal value of 1 and 0 respectively for the inferior and the superior competitors when the full competitive exclusion was reached. At low intensity of negative feedback (20\%), RCI values maintained the same qualitative dynamics as the previous case, with a value close to 1 for the inferior competitor reflecting the very low population density compared to the monoculture without interspecific competition. On the contrary, at intermediate level of negative feedback $(50 \%)$ species interactions show changing trends with a competitive first phase of simulation for both species (Fig. 5) followed by negative RCI values. This reflected the fact that both species had a higher population density in mixture than in monoculture. The RCI value was more negative for the inferior competitor because this species had a higher advantage from the interspecific interaction. At the maximal intensity of negative feedback $(100 \%)$, species interaction still shifted from a competitive to a facilitative pattern with RCI values dropping to $-\infty$. This is as expected because species with $100 \%$ of negative feedback are unable to grow on their own substrate and consequently die out in monoculture.

Systematic analysis of the model simulation results showed that, with increasing competitive strength between species, higher negative feedback intensities are needed in order to allow a stable coexistence (Fig. 6). Positive species interactions occur only with negative feedback intensity above a value of $35 \%$, i.e. a more restrictive condition than that required for a sustainable coexistence.

\section{Vegetation removal experiments}

The disturbance simulation exercise was carried out on a modelled stable plant community characterised by a functional equilibrium of two species both with a $50 \%$ negative feedback level (Fig. 2). The complete and abrupt removal of a species was followed by a growth 


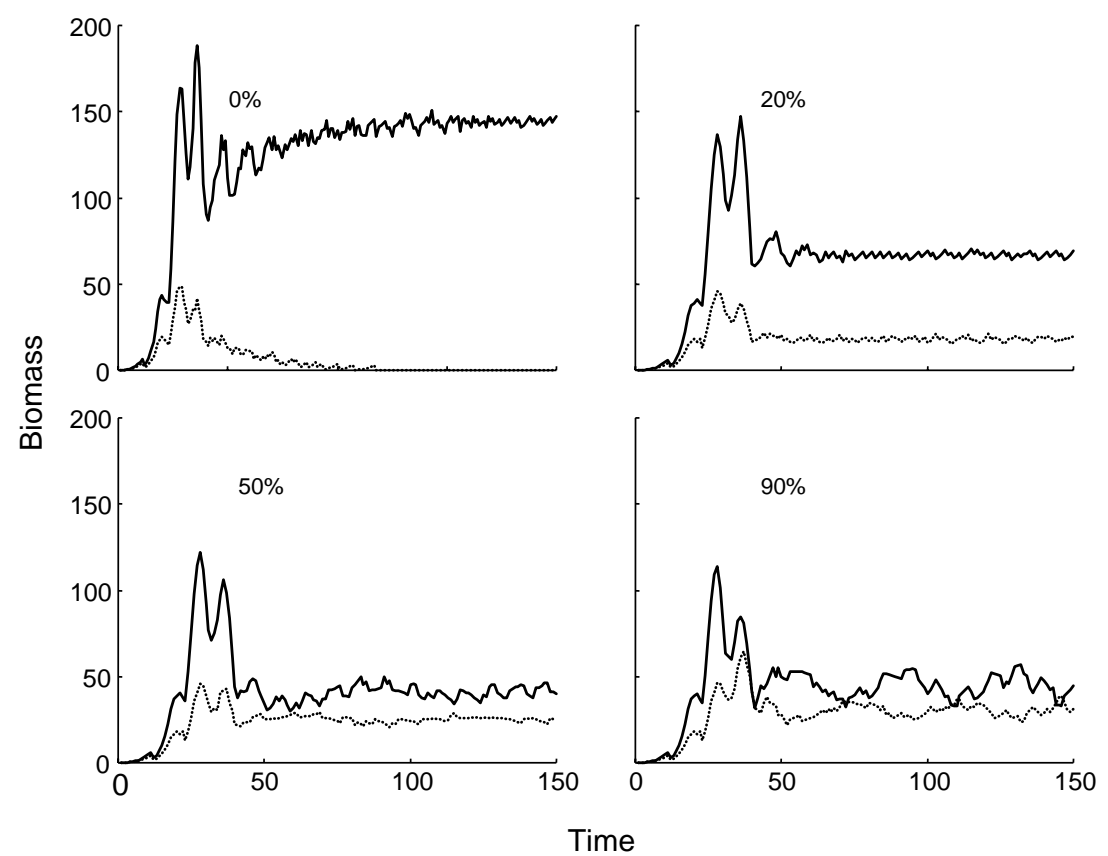

Fig. 2. Effects of negative feedback on competition between two species during a secondary succession process. Without negative feedback the inferior competitor $(\mathrm{a}=0.5$; dotted line $)$ was competitively excluded from the community, with the reaching of full dominance by the other species $(\mathrm{a}=0.6$; solid line). The presence of negative feedback on both species allows a stable coexistence at all intensity levels $(\mathrm{NF}=0.2,0.5$ and 0.9$)$.

flush of the remaining one due to the elimination of the interspecific competitive effect. The magnitude of the post disturbance growth recovery indicates the intensity of the competitive release of the remaining species (data not shown). However, in the presence of negative feedback, after this early positive effect, the remaining species showed a subsequent population decline, reaching a new equilibrium at a lower level than the initial mixed community condition (Fig. 7). These results are interesting because the remaining species showed higher biomass values in presence of interspecific competition than alone. The observed population decline is the consequence of the development of a negative feedback in the soil in the absence of the indirect positive effect of the removed species. The simulation also showed a timelag between vegetation removal and the build-up of the negative plant-soil interaction. It should be noted that this timelag is longer than the species lifecycle length (Fig. 7). Conversely, without negative feedback, these post-disturbance dynamics would be absent and, at equilibrium, the population size of the remaining species would be higher than in the presence of these interspecific interactions.

\section{Discussion}

\section{The role of negative feedback on species dynamics and coexistence}

Classical views of primary succession are based on facilitation and competition (Connel and Slatyer 1977, Tilman 1988). However, experimental evidence is now available on the presence of negative feedback on early successional species, such as nitrogen-fixing perennials scrubs (Oremus and Otten 1981, Walker 1993, Chapin et al. 1994) grasses and sedges (Keever 1950, Van der Putten et al. 1993) and pioneer tree species in tropical and temperate forest (Webb et al. 1967, Richards 1996, Packer and Clay 2000, Anderson et al. 2002). The addition in the model of negative feedback for the pioneer species generated a faster species succession. This was due to a lower competitive ability of the pioneer species on soil patches derived from conspecific mortality compared to simulations without negative feedback. A possible explanation for the scarce attention paid to negative feedback in successional theory, compared to other mechanisms such as competition and facilitation, may be related to its qualitative effect which acts in the same direction of the competition effect. This makes experimental investigation and the isolation of its effects from other complementary successional mechanisms difficult.

In relation to species coexistence, the modelling exercise showed how negative feedback allowed the coexistence of competing species, although their relative abundance at equilibrium could differ according to the intensity of the feedback and the species number. An important outcome was that even very low negative feedback intensity enabled the survival of the inferior competitors (Fig. 2, 3). However, it has been recognised that limited populations can face stochastic extinction after large disturbance events (May 1974, Tilman 1994), thus suggesting that very low negative feedback alone could not allow a stable coexistence between strong competitors if there are frequent disturbances. In any 
Fig. 3. Effects of negative according to species number during a secondary succession process (left: two species; middle: three species presence of negative feedback avoids the the inferior competitors. For all simulation the growth rates of species are 0.60 and 0.55 for two species interaction; $0.60,0.55$ and line), 0.55 (dotted line), 0.50 (bold dotted line) and 0.45 (dashed line) for four species interaction. feedback on competition and right: four species). The competitive exclusion of all 0.50 for three species interaction and 0.60 (solid
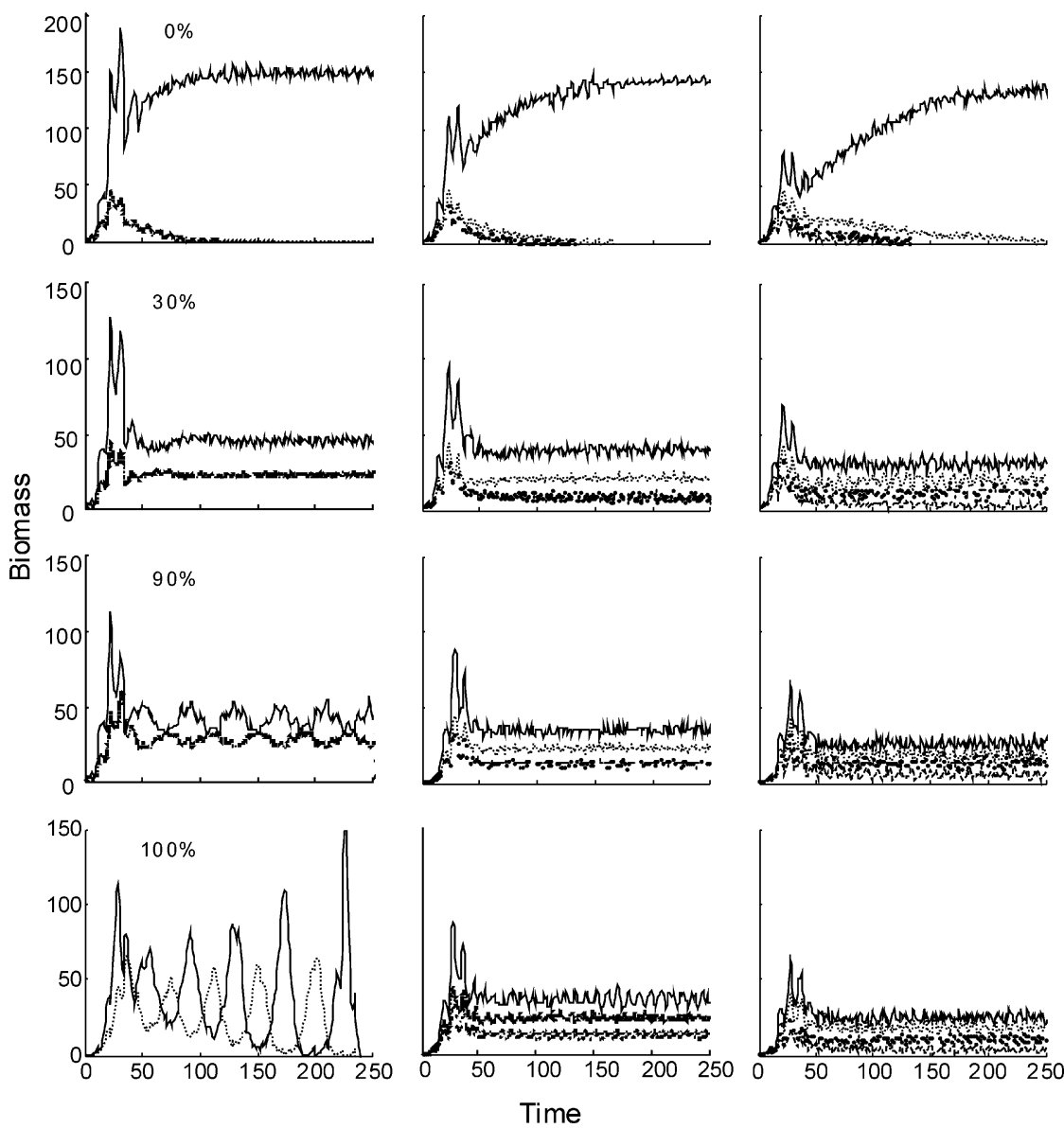

case, at intermediate levels of negative feedback species coexistence is stable and all species have a relatively high abundance. In contrast, in the case of two competing species, very high levels of negative plant-soil feedback generated large population fluctuations with alternating species dominance, as produced in the simulations of

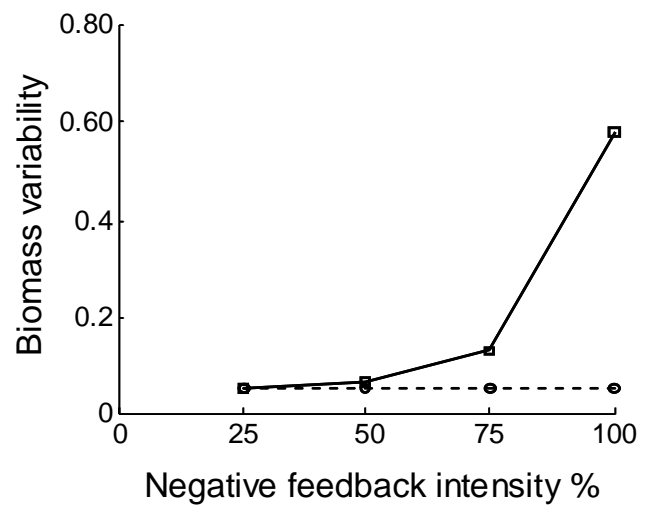

Fig. 4. Stability of population density according to negative feedback levels. Coefficient of variability was calculated from simulation of Fig. 3, between time steps 50 and 150, i.e. until reaching of stability conditions. Solid and dotted lines refer to two and three species interactions respectively.
Bever (2003). Again, in this condition species populations can become subject to stochastic extinction when the population sizes are low. Interestingly, we showed a positive effect of the species diversity on population

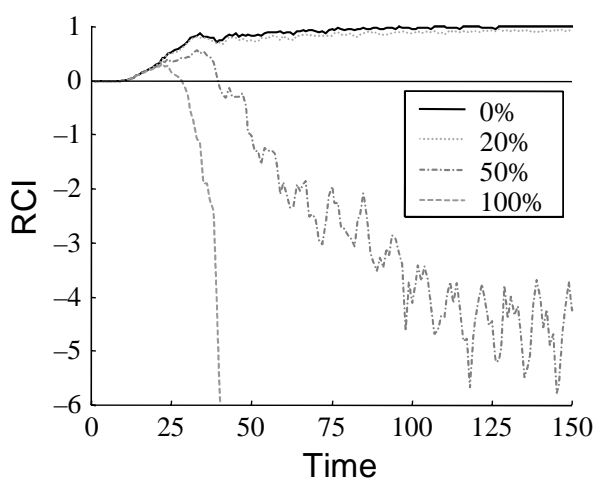

Fig. 5. Effects of negative feedback on two species interactions during a simulated secondary succession process. The relative competition index (RCI) for the inferior competitor shows always a competitive interaction with no and low levels of negative feedback $(0 \%, 20 \%)$. With higher negative feedback levels $(50 \%$ and $100 \%)$ the species interaction shifts during the simulations from competitive to a facilitative outcomes. Simulation species parameters as in Fig. 2, and negative feedback intensity $(\%)$ is indicated in the graph. 


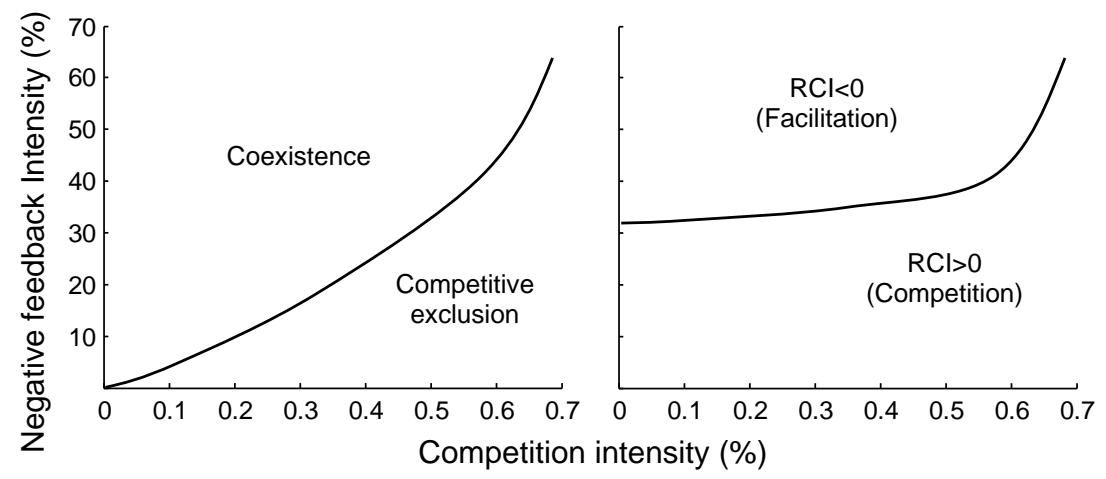

Fig. 6. Minimal necessary conditions of negative feedback for stable coexistence (left) and positive interspecific interaction (right) in relation to competition intensity $(\%$ differences between growth rates of two competing species). Results refer to the simulation outcome for the inferior competitor at equilibrium conditions. Lines show threshold levels and represent graphical fitting of repeated simulation exercises. stability in the presence of high negative feedback levels. In fact, increasing species number reduced the fluctuations of population density (Fig. 3, 4). The possible explanations of such behaviour can be related to the higher probability for a species to find good establishment conditions (soil patches without negative feedback). As showed by Bever (2003) with a Lotka-Volterra model, and repeated in our individualbased model, a higher competitive strength requires a higher negative feedback intensity to allow stable coexistence.

In our model the mechanism of coexistence is the propensity for occupation by a species of space vacated by its competitor. In other words, there is a high likelihood of species exchange because of the varying competitive ability of the species on different substrates. Each species is less competitive on the soil derived from conspecific mortality, i.e. on the soil that supported the growth of the same species. Increasing the intensity of negative feedback induced a greater species turnover both in time and space (Fig. 5). These simulation results

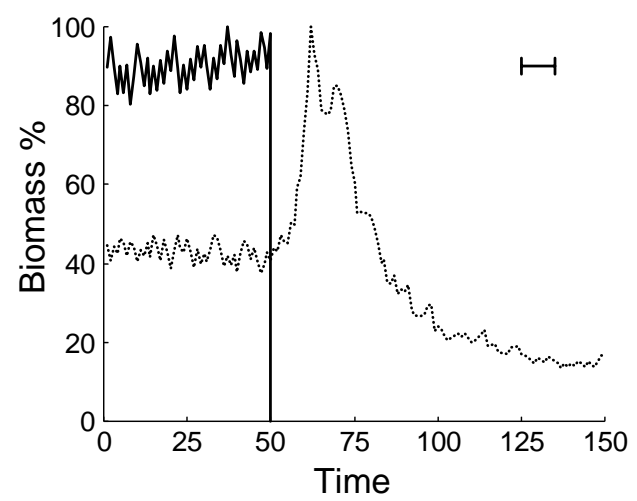

Fig. 7. Simulation of a removal experiment on a simplified two species plant community characterised by a functional equilibrium by a $50 \%$ negative feedback intensity for both species (Fig. 2). After the removal of competitor (solid line), an initial growth flush of the remaining species (dotted line) is followed by a strong decline and a new equilibrium at lower level. Simulation species parameters as in Fig. 2, bar length indicate species life span. have support from several experimental studies, for example agricultural crop rotation is a very common soil management strategy aimed at avoiding negative plant-soil interactions created by repeated monosuccession or too narrow crop rotation (Zucconi 1996). On the other hand, in natural conditions species alternation in time and space has also been reported in forest ecosystems (Fox 1977, Whittaker and Levin 1977), shrub-land (Watt 1947, Pedemasa 1981) and grassland (Turkington and Harper 1979, van der Maarel and Sykes 1993). Although inferences about plant community processes are difficult to obtain on the basis of only spatio-temporal patterns (Molofsky et al. 2002), the model presented here suggests an experimentally testable mechanism for these common, but poorly understood, plant community dynamics.

\section{Negative feedback as a facilitation mechanism}

In our model, when the available space is limiting for population growth, species interact by direct competition. In the absence of negative feedback, species interaction is always competitive throughout the whole simulation period (Fig. 5). Unexpectedly and counter intuitively, above a critical level of negative feedback, species interaction appeared to be strongly timescale dependent (Fig. 5). In fact, in an initial phase of the simulation competitive interactions are present, but when approaching the equilibrium conditions, a higher population of both species are maintained in mixtures compared to monocultures, reflecting an indirect positive reciprocal interaction (Fig. 5). This positive effect is created by the reciprocal alternation of plants in the free space following the mortality of the individuals of different species. Higher negative feedback levels are necessary at higher competition intensity in order to produce a positive interaction between competing species (Fig. 6).

Reciprocal interspecific positive interactions are common in nature, for example in the case of symbiosis between mycorrhizal fungi or nitrogen-fixing bacteria 
and plants. This type of relationship implies a direct and contemporary exchange of positive effects (Alcock 1998). When a direct positive interaction is present, the system is subject to the penetration of individual "cheaters" which gain advantage without any energy or time cost (Trivers 1971, Axelrod and Hamilton 1981, Alcock 1998). This mechanism allowed the evolution of reciprocal altruism in animals in very resource limited conditions (Wilkinson 1984) characterised by a specific equilibrium between "cheaters" and cooperative individuals. However, this is not the case for our model where the species turnover in space and time is not due to a direct interaction between plants, but it is generated by the different competitive ability in the substrate use according to the release of space by species mortality.

Experimental evidence of reciprocal positive interaction is very rare for higher plants (but see Pugnaire et al. 1996), being mostly restricted at commensalic or amensalic relationships in stressed environments (Bertness and Hacker 1994, Callaway 1995, Callaway and Walker 1997, Bruno et al. 2003). In poorly productive and stressed communities the removal of "nurse" plants, because of their multifactorial effects on environmental conditions, produces the simultaneous elimination of competitive and facilitative interactions. On the other hand, competitive interaction is the commonest result of removal experiments in productive plant communities (Connell 1983, Goldberg and Barton 1992, Rajaniemi et al. 2003). We believe that our model supports a theoretical framework for a clarification of the complicated and controversial issue of species interaction. Our hypothesis is that indirect positive interaction due to negative feedback is an important structuring force of plant communities, which is not restricted to stressed environments. In the simulation of vegetation removal (Fig. 7), in agreement with the experimental reports mentioned above, the elimination of one species generated a strong growth flush, i.e. a competitive release of the remaining species population. However, the same simulation also showed a longterm negative response due to the rise of negative feedback in the soil conditions. With vegetation removal the competitive release is immediate, i.e. elimination of competitive effect, whereas a timelag occurs before the positive indirect interaction between species becomes evident. Such delayed response depends on the build-up of negative feedback in the available soil whilst under the influence of the same species. Most of the empirical tests used to investigate species interaction, e.g. additional, replacement and removal tests, are short-term usually less than one year long experiments (Connell 1983, Goldberg and Barton 1992, Diaz et al. 2003). This period is much shorter than the lifespan of longlived perennial species thus making these experiments unable to show the hypothesized transient dynamics of species response to vegetation removal. Longterm experiments are needed to test the hypothesis generated by our model. However, indirect evidence that supports our theoretical interpretation can be found in longterm experiments on the effects of biodiversity on community functions, commonly referred to as synthetic-assemblage experiments (Hector 2001, Diaz et al. 2003). Reduction or even collapse of productivity, after an initial period of active growth, has been reported for several monoculture treatments (Wedin and Tilman 1993, Pfisterer and Schmid 2002). The rise of plant-soil negative feedback might be one of the functional mechanisms behind the positive effect of biodiversity on productivity during longterm experiments (Tilman et al. 2001). In this way, plant-soil negative feedback might be a mechanism for overyielding by generating a niche complementarity between different species for soil use in both time and space. This complementarity effect would require a timelag as shown by the removal simulation (Fig. 7) and which seems coherent with the results of longterm synthetic assemblage community experiments (Tilman et al. 2001).

\section{Conclusion}

Our model, in agreement with previous modelling work (Bever et al. 1997, Bever 2003), supports the theory that negative feedback between individuals of competing species should be taken into account as another relevant mechanism for species coexistence. Its relation and relative importance to other coexistence mechanisms in different plant communities remains an open issue for further research.

Moreover, the model shows how negative feedback could generate a positive reciprocal interspecific interaction at the population level, despite the lack of a direct positive effect between individuals. A reciprocal facilitation becomes possible only if negative feedback affects all species and if plants have enough time to interact. Then, this reciprocal cooperation is the consequence of community organization because of the reciprocal and alternate use of the available space by the different species. This has a more positive effect than the direct (negative) competitive effect for the same space.

Although the model presented here is only a very simplified model of plant community, it shows the role of negative feedback on individuals interaction, population dynamics and community organization, which can be considered testable hypotheses to assess different community spatial-patterns. Vegetative propagation (Van der Putten et al. 1993, Olff et al. 2000) and seed dispersal (Packer and Clay 2000) capability should be common as possible escape mechanisms to avoid negative feedback conditions. Future studies should be based on spatiallyexplicit models for further investigation of the role of plant-soil negative feedback on the spatial organization of plant communities. Moreover, the presence of plantsoil feedback cross effects between different species 
should be also considered in further analysis to increase our understanding of plant coexistence.

Acknowledgements - We sincerely thank Prof. Franco Zucconi for his stimulating teaching and discussion on the subject of plant-soil interactions. Davide Neri and Max Rietkerk provided useful discussion on this work. We are grateful to Dr. Sebastian Diehl and Dr. Mark Mulligan for their in depth knowledge and very useful comments on earlier versions of the paper.

\section{References}

Aarssen, L. W. and Epp, G. A. 1990. Neighbours manipulations in natural vegetation: a review. - J. Veg. Sci. 1: 13-30.

Alcock, J. 1998. Animal behavior: an evolutionary approach - M.A. Sinauer.

Anderson, R. C., Gardner, D. E., Daehler, C. C. et al. 2002. Dieback of Acacia koa in Hawaii: ecological and pathological characteristics of affected stands. - For. Ecol. Manage. 162: $273-286$.

Armstrong, J. and Armstrong, W. 2001. An overview of the effects of phytotoxins on in relation to die-back. - Aquat. Bot. 69: 251-268.

Axelrod, R. and Hamilton, W. D. 1981. The evolution of cooperation. - Science 211: 1390-1396.

Bertness, D. and Hacker, D. 1994. Physical stress and positive associations among marsh plants. - Am. Nat. 144: 363372.

Bever, D. J. 1994. Feedback between plants ant their soil communities in an old field community. - Ecology 75: $1965-1977$.

Bever, D. J. 2003. Soil community feedback and the coexistence of competitors: conceptual frameworks and empirical tests. - New Phytol. 157: 465-473.

Bever, D. J., Westover, M. and Antonavics, J. 1997. Incorporating the soil community into plant population dynamics: the utility of the feedback approach. - J. Ecol. 85: 561-573.

Blomqvist, M. M., Olff, H., Blaauw, M. B. et al. 2000. Interaction between above- and below ground biota: importance of small scale vegetation mosaic in a grassland ecosystem. - Oikos 90: 582-598.

Bruno, F., Stachowicz, J. and Bertness, M. 2003. Inclusion of facilitation into ecological theory. - Trends Ecol. Evol. 18: $119-125$.

Callaway, R. M. 1995. Positive interaction among plants. - Biol. Rev. 61: 306-349.

Callaway, R. M. and Walker, R. 1997. Competition and facilitation: a synthetic approach to interaction in plant communities. - Ecology 78: 1958-1965.

Chapin, S. III, Walker, R., Fastie, L. et al. 1994. Mechanism of primary succession following deglaciation at Glacier Bay, Alaska. - Ecol. Monogr. 64: 149-175.

Chesson, P. 2000. Mechanisms of maintenance of species diversity. - Annu. Rev. Ecol. Syst. 31: 343-366.

Chou, C. and Lin, H. 1976. Autointoxication mechanism of Oryza sativa. Phytotoxic effects of decompositing rice residues in soil. - J. Chem. Ecol. 2: 353-367.

Connell, J. H. 1978. Diversity in tropical rain forest and coral reefs. - Science 199: 1302-1310.

Connell, J. H. 1983. On the prevalence and importance of interspecific competition: evidence from field experiments. - Am. Nat. 122: 661-696.

Connel, J. H. and Slatyer, R. O. 1977. Mechanisms of succession in natural communities and their role in community stability and organization. - Am. Nat. 111: 1119-1144.

De Rooij-van Der Goes, P. C. E. M. 1995. The role of plantparasitic nematodes and soil-borne fungi in the decline of Ammophila arenaria L. Link. - New Phytol. 129: 661-669.
DeAngelis, D. L. and Gross, L. J. 1992. Individual-based models and approaches in ecology. - Chapman and Hall.

Diaz, S., Symstad, J., Chapin III, S. et al. 2003. Functional diversity revealed by removal experiments. - Trends Ecol. Evol. 18: 140-146.

Fargione, J. and Tilman, D. 2002. Competition and coexistence in terrestrial plants. - In: Sommer, U. and Worm, B. (eds), Competition and coexistence. Springer, pp. 165-198.

Fitter, A. H. 1986. Spatial and temporal patterns of root activity in a species-rich alluvional grassland. - Oecologia (Berlin) 69: $594-599$.

Florence, R. G. 1965. Decline of old-growth redwood forests in relation to some soil microbiological process. - Ecology 46: $52-64$.

Fox, J. F. 1977. Alternation and coexistence of tree species. - Am. Nat. 111: 69-89.

Goldberg, D. E. and Barton, A. M. 1992. Patterns and consequences of interspecific competition in natural communities: a review of field experiments with plants. - Am. Nat. 139: 771-801.

Grace, J. B. 1995. On the measurement of plant competition intensity. - Ecology 76: 305-308.

Grime, J. P. 1979. Plant strategy and vegetation processes. - John Wiley and Sons.

Grimm, V. 1999. Ten years of individual-based modelling in ecology: what have we learned and what could we learn in the future? - Ecol. Modell. 115: 129-148.

Grubb, P. J. 1977. The maintenance of species-richness in plant communities: the importance of the regeneration niche. - Biol. Rev. 52: 107-145.

Hector, A. 2001. Biodiversity and the functioning of grassland ecosystems: multi-site comparison. - In: Kinzing, P., Pacala, S. and Tilman, D. (eds), The functional consequences of biodiversity. Monogr. Popul. Biol., Princeton Univ. Press, pp. $71-95$.

Holah, J. and Alexander, H. M. 1999. Soil pathogenic fungi have the potential to affect the coexistence of two tallgrass prairie species. - J. Ecol. 87: 598-608.

Huisman, J. and Weissing, F. J. 1999. Biodiversity of plankton by species oscillation and chaos. - Nature 402: 407-410.

Huston, M. A. 1994. Biological diversity: the coexistence of species on changing landscape. - Cambridge Univ. Press.

Hutchinson, G. E. 1958. Homage to Santa Rosalia, or why are there so many species of animals? - Am. Nat. 93: 145-159.

Keever, C. 1950. Cause of succession on old fields of the Piedmont, North Carolina. - Ecol. Monogr. 20: 229-250.

Klausmeier, C. A. and Tilman, D. 2002. Spatial models of competition. - In: Sommer, U. and Worm, B. (eds), Competition and coexistence. Springer, pp. 43-75.

Klironomos, J. N. 2002. Feedback with soil biota contributes to plant rarity and invasiveness in communities. - Nature 417: $67-70$.

Li, J. and Romane, F. 1997. Effect of germination inhibition on the dynamics of Quercus ilex stands. - J. Veg. Sci. 8: 287294.

Little, L. R. and Maun, M. A. 1996. The "Ammophila problem" revisitated: a role for mycorrhizal fungi. - J. Ecol. 84: 1-7.

May, R. 1974. Stability and complexity in model ecosystems. - Princeton Univ. Press.

McNaughton, S. J. 1968. Autotoxic feedback in relation to germination and seedling growth in Typha latifolia. - Ecology 49: 367-369.

Miles, J. and Walton, D. W. H. 1993. Primary succession on land. - In: Miles, J. and Walton, D. W. H. (eds), Blackwell Scientific Press.

Miller, D. A. 1996. Allelopathy in forage crop system. - Agron. J. 36: $854-859$.

Miller, T. E. 1994. Direct and indirect species interactions in an early old-field plant community. - Am. Nat. 143: 10071025.

Molofsky, J., Bever, D. J., Antonavics, J. et al. 2002. Negative frequency dependence and the importance of spatial scale. - Ecology 83: 21-27. 
Muetzelfeldt, R. and Massheder, J. 2003. The Simile visual modelling environment. - Eur. J. Agron. 18: 345-358.

Newman, E. I. and Rovira, D. A. 1975. Allelopathy among some British grassland species. - J. Ecol. 63: 727-737.

Olff, H., Hoorens, B., De Goede, R. G. M. et al. 2000. Smallscale shifting mosaic of two dominant grassland species: the possible role of soil borne pathogens. - Oecologia 125: 45-54.

Oremus, P. A. I. and Otten, H. 1981. Factor affecting growth and nodulation of Hippophaë rhamnoides L. ssp. rhamnoides in soils from two successional stages of dune formation. - Plant Soil 63: 317-331.

Packer, A. and Clay, K. 2000. Soil pathogens and spatial patterns of seedling mortality in a temperate tree. - Nature 404: $278-280$.

Paine, R. T. 1966. Food web complexity and species diversity. - Am. Nat. 100: 65-76.

Patrick, Z. A. 1971. Phytotoxic substance associated with the decomposition in soil of plant residues. - Soil Sci. 111: 13-18.

Patrick, Z. A., Toussoun, T. A. and Snyder, W. C. 1963. Phytotoxicity substance in arable soils associated with decomposition of plant residues. - Phytopatology 53: $152-161$.

Pedemasa, M. 1981. Cyclic change and pattern in Arthrocnemum community in Sri Lanka. - J. Ecol. 69: 565-574.

Pfisterer, A. B. and Schmid, B. 2002. Diversity-dependent production can decrease the stability of ecosystem functioning. - Nature 416: 84-86.

Proebsting, E. and Gilmore, E. 1940. The relation of peach root toxicity to the establishment of peach archards. - Am. Soc. Horticult. Sci. Proc. 38: 21-26.

Pugnaire, F. I., Haase, P. and Puigdefábregas, J. 1996. Facilitation between higher plant species in a semiarid environment. - Ecology 77: 1420-1426.

Rajaniemi, K., Allison, V. and Goldberg, D. 2003. Root competition can cause a decline in diversity with increasing productivity. - J. Ecol. 91: 407-416.

Rice, E. L. 1984. Allelophaty, 2nd ed. - Academic Press.

Richards, P. W. 1996. The tropical rain forest: an ecological study, 2nd edn. - Cambridge Univ. Press.

Singh, H. P., Batish, R. D. and Kohli, K. R. 1999. Autotoxicity: concept, organisms and ecological significance. - Crit. Rev. Plant Sci. 18: 757-772.

Sousa, W. P. 1984. The role of disturbance in natural communities. - Annu. Rev. Ecol. Syst. 15: 353-391.

Streng, R. D., Glitzenstein, J. S. and Harcombe, P. A. 1989. Woody seedling dynamics in a east Texas floodplain in forest. - Ecol. Monogr. 59: 177-204.

Tilman, D. 1985. The resource-ratio hypothesis of succession. - Am. Nat. 125: 827-852.

Tilman, D. 1988. Plant strategies and the dynamics and structure of plant communities. - Princeton Univ. Press.

Tilman, D. 1994. Competition and biodiversity in spatially structured habitats. - Ecology 75: 2-16.

Tilman, D. and Pacala, S. 1993. The maintenance of species richness in plant communities. - In: Ricklefs, R. E. and Schulter, D. (eds), Species diversity in ecological communities. Univ. of Chicago Press, pp. 13-25.

Tilman, D. and Lehman, C. 2001. Biodiversity, composition, and ecosystem processes: theory and concepts. - In: Kinzing, P., Pacala, S. and Tilman, D. (eds), The functional consequences of biodiversity. Monogr. Popul. Biol., Princeton Univ. Press, pp. 9-41.

Tilman, D., Reich, P. B., Knops, J. et al. 2001. Diversity and productivity in a longterm grassland experiment. - Science 294: $843-845$.
Trivers, R. L. 1971. The evolution of reciprocal altruism. - Q. Rev. Biol. 46: 35-57.

Turkington, R. and Harper, J. L. 1979. The growth, distribution, and neighbour relationships of Trifolium repens in a permanent pasture. I. Ordination, pattern and contact. - J. Ecol. 67: 201-218.

Uchmanski, J. and Grimm, V. 1996. Individual-based modelling in ecology. What makes the difference? - Trends Ecol. Evol. 11: $437-441$.

van der Maarel, E. and Sykes, M. T. 1993. Small-scale plant species turnover in a limestone grassland: the carousel model and some comments on the niche concept. - J. Veg. Sci. 4: $179-188$.

Van der Putten, W.H. 2003. Plant defense belowground and spatiotemporal processes in natural vegetation. - Ecology 84: $2269-2280$.

Van der Putten, W. H. and Peters, B. A. M. 1997. How soilborne pathogens may affect plant competition. - Ecology 78: $1785-1795$.

Van der Putten, W. H., Van Dijk, C. and Troelstra, S. R. 1988. Biotic soil factors affecting the growth and development of Ammophila arenaria. - Oecologia 76: 313-320.

Van der Putten, W. H., Van Dijk, C. and Peters, B. A. M. 1993. Plant-specific soil-borne diseases contribute to succession in foredune vegetation. - Nature 362: 53-56.

Walker, L. R. 1993. Nitrogen fixers and species replacements in primary succession. - In: Miles, J. and Walton, D. W. H. (eds), Primary succession on land. Blackwell Scientific, pp. 249-272.

Waller, R., Kumari, D. and Friedman, J. 1986. Caffeine autotoxicity in Coffea arabica. - In: Putnam, A. R. and Tang, C. S. (eds), The science of allelophaty. Wiley.

Watt, A. S. 1947. Pattern and process in the plant community. - J. Ecol. 35: 1-22.

Webb, L. J., Tracey, J. G. and Haydock, K. P. 1967. A factor toxic to seedlings of the same species associated with living roots of the non-gregarious subtropical rain forest tree Grevillea robusta. - J. Appl. Ecol. 4: 13-25.

Wedin, D. and Tilman, D. 1993. Competition among grasses along a nitrogen gradient: initial conditions and mechanisms of competition. - Ecol. Monogr. 63: 199-229.

Weiner, J. 1990. Asymmetric competition in plant populations. - Trends Ecol. Evol. 5: 360-364.

Whittaker, R. H. and Levin, S. A. 1977. The role of mosaic phenomena in natural communities. - Theor. Popul. Biol. 12: $117-139$.

Wilkinson, G. W. 1984. Reciprocal food sharing in the vampire bat. - Nature 308: 181-184.

Wills, C., Condit, R., Foster, R. B. et al. 1997. Strong densityand diversity-related effects help to maintain tree species diversity in a neotropical forest. - Proc. Natl Acad. Sci. 94: $1252-1257$.

Worm, B. and Karez, R. 2002. Competition, coexistence and diversity on rocky shores. - In: Sommer, U. and Worm, B. (eds), Competition and coexistence. Springer, pp. 133-158.

Zucconi, F. 1994. Root dynamics in natural and agricultural plants and the making of domestication. In: Proc. Int. workshop: Dynamics of roots and nitrogen in cropping system of the semi-arid tropics. Patancheru, Andhra Pradesh, India, November 1994.

Zucconi, F. 1996. Declino del suolo e stanchezza del terreno. - Spazio Verde Padova.

Subject Editor: Heikki Setälä 